\title{
Frailty and osteoporosis in patients with hip fractures under the age of 60-a prospective cohort of 218 individuals
}

\author{
Sebastian Strøm Rönnquist ${ }^{1}{ }^{1} \cdot$ Bjarke Viberg $^{2} \cdot$ Morten Tange Kristensen $^{3,4,5} \cdot$ Henrik Palm $^{6}$. \\ Jens-Erik Beck Jensen ${ }^{5,7} \cdot$ Carsten Fladmose Madsen $^{8} \cdot$ Kristina E. Åkesson $^{9,10}$. Søren Overgaard ${ }^{11,12}$. \\ Cecilia Rogmark ${ }^{1}$
}

Received: 27 October 2021 / Accepted: 20 December 2021 / Published online: 14 January 2022

(c) The Author(s) 2022

\begin{abstract}
Summary Research on younger patients with hip fractures is limited. This study adds knowledge on patient and injury characteristics, and DXA was investigated at the time of the fracture. Risk factors for osteoporosis and fractures were numerous among young patients, and osteoporosis was markedly more prevalent than in the general population.

Introduction Knowledge on younger patients with hip fractures is limited. Common preconceptions are that they suffer fractures due to high-energy trauma, alcohol or substance use disorder but not associated to osteoporosis. We aimed to descriptively analyze the characteristics of young and middle-aged patients with hip fractures and examine bone mineral density (BMD) by dual-energy x-ray absorptiometry (DXA) at the time of the fracture.

Methods A prospective multicenter cohort study on adult patients with hip fractures below age 60 collected detailed information on patient characteristics regarding demographics, trauma mechanism, previous fractures, comorbidity and medication, and lifestyle factors. DXA results were compared to population-based reference data.

Results The cohort contains 91 women and 127 men, median age 53 (IQR 47-57). Most fractures, 83\%, occurred in patients aged 45-59. Two-thirds of all fractures resulted from low-energy trauma. Half of the patients had prior fractures after age 20. Thirty-four percent were healthy, $31 \%$ had one previous disease, and $35 \%$ had multiple comorbidities. Use of medication associated with increased fracture risk was $32 \%$. Smoking was prevalent in $42 \%$, harmful alcohol use reported by $29 \%$, and signs of drug-related problems by $8 \%$. Osteoporosis according to WHO criteria was found in $31 \%$, osteopenia in $57 \%$, and normal BMD in $12 \%$.

Conclusion In patients with hip fractures below age 60, risk factors for osteoporosis and fractures were numerous. Moreover, the prevalence of osteoporosis was markedly higher than in the general population. We suggest that young and middle-aged patients with hip fractures undergo a thorough health investigation including DXA, regardless of trauma mechanism.
\end{abstract}

Keywords DXA $\cdot$ Epidemiology $\cdot$ Hip fracture $\cdot$ Osteoporosis $\cdot$ Young and middle-aged adults

\section{Introduction}

Young and middle-aged patients constitute one-tenth of the total hip fracture population [1-4], but the literature is scarce concerning this patient group in comparison to the elderly. Nevertheless, many orthopaedic surgeons have preconceptions regarding who these patients are. Common perceptions are that younger patients suffer hip fractures due to

Sebastian Strøm Rönnquist

sebastian.strom_ronnquist@med.lu.se

Extended author information available on the last page of the article high-energy trauma, alcohol or substance use disorder but not due to osteoporosis [5, 6].

These preconceptions could emanate from older studies or studies from low- and middle-income countries, depicting high-energy trauma to be the main cause of hip fractures in younger patients, thereby dismissing any risk of osteopenia and osteoporosis $[3,7,8]$. Studies on samples representing the general Western world population of today suggest that young and middle-aged patients may have both osteopenia and osteoporosis regardless of trauma mechanism [1, 2, 9-12]. However, there are considerable limitations to these studies; conclusions on bone health were not based on dualenergy x-ray absorptiometry (DXA) investigation at the time 
of the fracture but solely on risk factors for osteoporosis, or on DXA measurement years after the hip fracture [1, 2, 9-11]. Only one smaller previous study performed DXA at the time of the hip fracture and found a high rate of low bone mineral density (BMD) in patients aged under 70 years [12].

We designed a prospective multicenter cohort study that assessed BMD by DXA at the time of the hip fracture in adults under 60 years of age and performed comparisons to other DXA reference materials. In addition, detailed information on patient and injury characteristics was obtained as this is not previously well investigated. This is the primary report on baseline results from the "Hip Fracture in adults Under 60 years of age" project (HFU-60), describing the demography and epidemiology of hip fractures in young and middle-aged patients, as well as lifestyle factors, comorbidity, and general health in the cohort together with analysis of DXA results.

\section{Aims}

In patients with hip fractures under the age of 60 years, we aimed to descriptively analyze their characteristics, with a focus on risk factors for fractures and osteoporosis, and describe BMD at the time of the hip fracture related to known normal values in the population.

\section{Material and methods}

\section{Settings}

Patients were included at any of the participating 4 departments of orthopaedics and traumatology in Southern Scandinavia - Lillebaelt Hospital, Odense University Hospital, and Copenhagen University Hospital Hvidovre (Denmark) and Skåne University Hospital Malmö (Sweden). Public health care is provided in both Denmark and Sweden. There is no cost for the patients in Denmark and a small patients' fee in Sweden. The departments participating in the study provide basic and advanced orthopaedic care within their local hospitals and also function as trauma centers for patients in their catchment areas. All hip fracture treatment within the catchment areas is performed at the participating orthopaedic departments. As the aim of the study was to describe the cohort, we did not perform comparisons between the departments or the countries; all included patients were regarded as one common cohort.

\section{Participants}

Patients aged 18 to 59 years, who sustained an acute hip fracture (defined by ICD codes S72.00, S72.10, and S72.20) and treated within 4 weeks at any of the participating departments, were eligible for inclusion in the study regardless of medical, cognitive, and functional pre-fracture status. Pathological fractures, i.e. due to tumour or metastases, were excluded. Other concomitant injuries were not a reason for exclusion from the study. The patients' informed consent was obtained before inclusion in the study. Malmö started the inclusion in HFU-60 in July 2015 , followed by the other centers in the first half of 2016. Inclusion was closed at all departments 31 Dec 2018.

\section{Data collection}

As we have collected multiple variables, all collected data is specified and defined in Appendix Table 5. Data on study participants was retrieved by the following means:

- Review of medical records and patient interviews

Medical charts were reviewed in each hospital. Patients were structurally interviewed post-operatively according to a questionnaire regarding lifestyle and health-related topics in addition to medical history.

From medical charts and patient interview, previous diseases and pharmacological treatment during 5 years prior to the hip fracture as well as information on the present injury were recorded. Review of the literature and expert discussions in the research group led to a selection of specific diseases and pharmacological treatments that may affect the risk of hip fracture (Appendix Tables 6 and 7), the conditions and drugs were chosen due to their known or presumed effects on bone mass, risk of falling, or the ability to hinder or modulate a fall $[1,5,6,13]$. The specific diseases and medical treatments were recorded, as well all other diagnoses and treatments present in the records. American Society of Anesthesiologists' (ASA) classification for the patients was assessed by the attending anesthesiologist pre-operatively and collected from medical charts [14]. The trauma mechanism was assessed and classified as either low-energy trauma, i.e. a fall from standing or a seated position, or not low-energy trauma if a higher degree of trauma energy led to the hip fracture.

- Physical activity assessment and functional test

The patients' pre-fracture physical activity level was measured by a validated questionnaire, the Swedish Board of Health and Welfare physical activity questions (BHW-PA), which is a categorical outcome instrument for assessment of physical activity [15]. The total physical activity score is a compound score of the time spent at physical exercise multiplied by two added to everyday physical activity time and is rated from minimal activity (3 points) to maximal activity (19 points) and a score of $\geq 11$ indicates fulfilment of recommended WHO activity of $\geq 150 \mathrm{~min} /$ week, previously confirmed by accelerometery $[16,17]$. In addition, the patients' hand grip strength was measured by a physiotherapist using a Jamar 
dynamometer; the best of three measurements with the dominant hand was used for analysis [18].

- Alcohol and drug use - patient-reported data

Alcohol and drug use were evaluated by the national versions of Alcohol Use Disorders Identification Test (AUDIT) and the Drug Use Disorders Identification Test (DUDIT) in Swedish and Danish. The written validated questionnaires on alcohol and drug use were filled out by the patients during admission regarding their situation preceding the hip fracture. AUDIT was developed by the WHO to identify hazardous or harmful alcohol use. DUDIT is originally a Swedish instrument to identify individuals with drug-related problems. Both have later been translated to multiple languages and are used internationally. AUDIT contains 10 items with a maximum score of 40 , and a score $\geq 6$ for women and $\geq 8$ for men indicates hazardous alcohol use. DUDIT holds 11 items on drug use, maximum score 44 , drug-related problems are indicated by $\geq 2$ for women and $\geq 6$ for men. [19-21]

- Laboratory assessment

Blood samples were part of the clinical work-up, taken both pre-operatively and post-operatively (Appendix Table 8). The local hospitals' accredited laboratory reference values were used as cut-off values for normal or pathological test results.

- Fracture classification

The hip fracture was classified as either intra- or extracapsular when a local researcher (orthopaedic surgeon) reviewed the pre-operative radiographs (AP and lateral view hip, AP pelvis).

- Bone mineral density investigation

DXA scans were performed at each hospital. Measurements were made at the lumbar spine and unfractured hip by local clinical standard regimes within 3 months postfracture. The DXA scanners used within the study came from two different manufacturers, General Electric and Hologic, and showed variability regarding the results on DXA phantom and human control scans. Therefore, we decided to use the DXA results without calibration, as this also represents the clinical setting at the local departments where patients were investigated and eventually diagnosed and treated according to DXA result. We defined osteopenia and osteoporosis by the WHO definitions according to $\mathrm{T}$-score (normal $\geq-1$, osteopenia -2.5 to -1 , osteoporosis $\leq-2.5)$, as proposed by the International Osteoporosis Foundation when investigating younger individuals [22]. The diagnosis was based on the lowest result on lumbar spine, femoral neck, or total hip T-scores, as these sites have been shown to decrease similarly with age [23]. Patients recently investigated by DXA prior to the hip fracture were not re-scanned; the pre-operative results were included in the analysis. Results for patients where DXA was performed later than 3 months post-fracture were excluded from analysis, as BMD has been shown to decrease with time after hip fracture [24]. Mean T-scores for the HFU-60 cohort were compared to the Third National Health and Nutrition Examination Survey (NHANES III) data for hip DXA scans, a sample of the general American population which serves as reference database for hip DXA scans performed on both General Electric and Hologic DXA scanners [25, 26].

\section{Bias}

The legislation on personal privacy prohibits us to perform a drop-out analysis of patients confirmed eligible but not included in the study; we cannot estimate the influence of selection bias.

\section{Study size}

The current study consists of all 218 eligible patients accepting participation during the inclusion period. The study is mainly descriptive; wherefore, power calculations were not considered necessary.

\section{Ethical considerations}

HFU-60 was approved by ethical review boards in Sweden (Regionala etikprövningsnämnden Lund (Diarienummer: 2015/28)) and Denmark (Videnskabsetisk Komité for Region Syddanmark (Projekt ID: s-20150137)), registered at ClinicalTrials.gov (NCT03848195), and conducted in accordance with the Helsinki declaration. All participants gave written informed consent.

\section{Statistics}

Data was collected locally and then stored online, available to the participating researchers via password log-in, using Research Electronic Data Capture (REDCap) (projectredcap.org). Analysis of data was performed centrally for all patients, using IBM SPSS version 26. Data was assessed for normality and continuous variables are presented as mean (SD) and median (IQR), depending on normal distribution or not. Analysis of associations in categorical variables was calculated using chi $^{2}$ test and $T$-test was used to compare means. Results are presented separately for women and men in order to describe the cohort most accurately. Patients were also grouped according to DXA result in order to describe risk factors for low BMD. 


\section{Results}

Of all patients with hip fractures treated at the departments during the study inclusion period, $6 \%$ were adults under the age of 60 years. A total of 91 women and 127 men were included in the study, 15 patients declined study participation and 52 eligible patients were not included (Fig. 1).

\section{Demographics}

Most hip fractures, $83 \%$, occurred in patients aged 45 to 59 years (Table 1 ). Women were overrepresented in the oldest age group, with $52 \%$ of the women versus $35 \%$ of the men being 55-59 years of age ( $p=0.009)$. Fifty-six percent of the patients were actively engaged on the labour market, $26 \%$ on early retirement due to poor health, and $11 \%$ were unemployed. Just over half of the patients lived together with another adult and 5\% (8\% of the men) resided in an institution. Half of the patients had a normal body mass index (BMI), and women were overrepresented in the underweight category $(p=0.023)$.

\section{The injury}

Two-thirds of the patients suffered their fracture due to low-energy trauma, i.e. a fall from standing or seated position, and more often women $(78 \%)$ than men $(61 \%)(p=0.007)$. Intracapsular fractures
Fig. 1 Flowchart of inclusion and analysis of DXA results
Potentially eligible $n=5525$

(patients with hip fractures at the departments during study inclusion time)

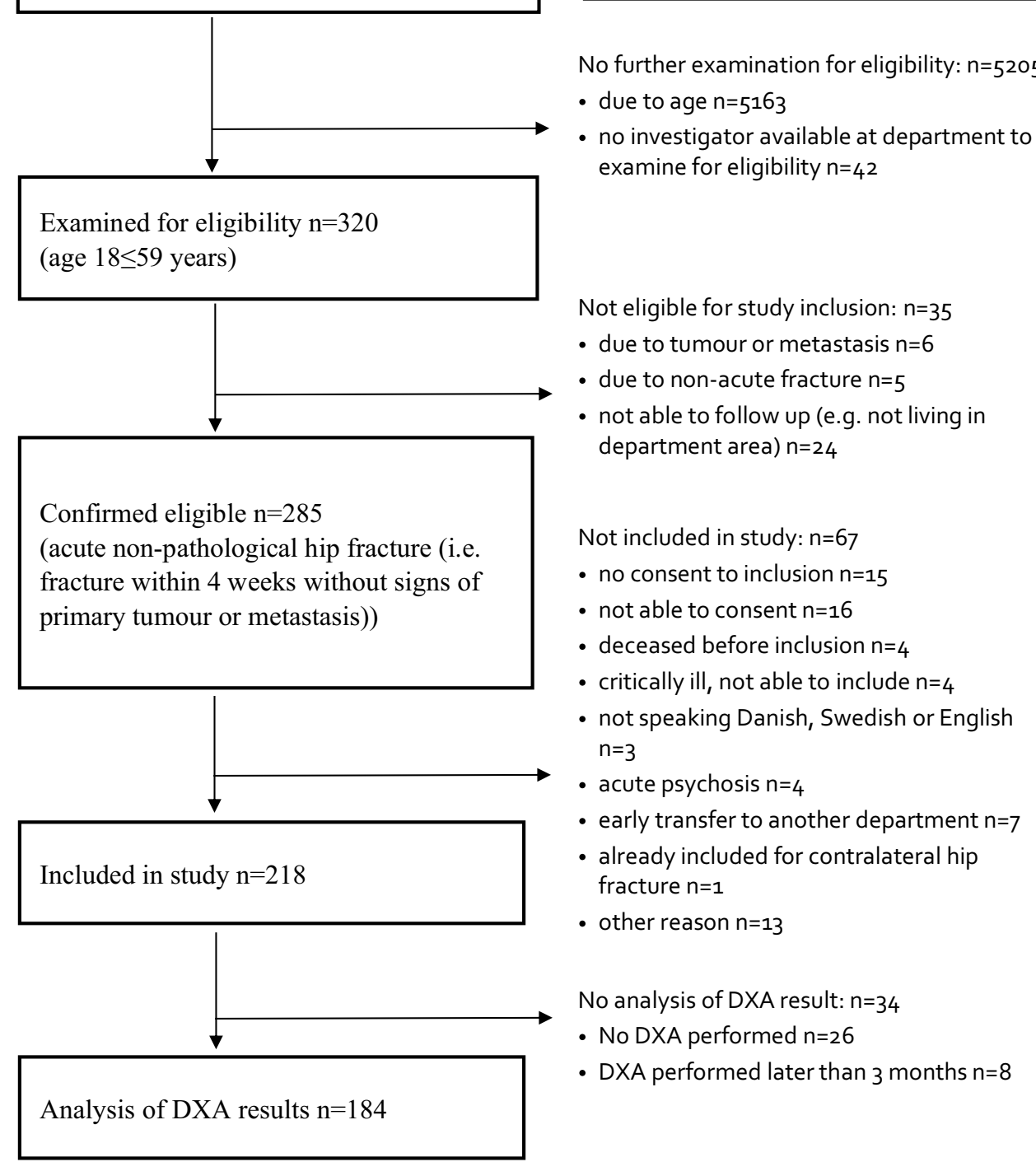

Hvidovre: Apr 2016-31 Dec 2018

Odense: $\quad$ May 2016-31 Dec 2018

Kolding: June 2016-31 Dec 2018

No further examination for eligibility: $n=5205$

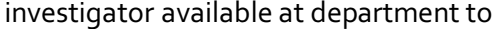

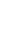

Malmö: July 2015 - 31 Dec 2018

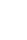
(1)

(1) 
Table 1 Patients' characteristics

\begin{tabular}{|c|c|c|c|}
\hline Age & Women $n=91$ & Men $n=127$ & Total $n=218$ \\
\hline Min-max & $23-59$ years & $28-59$ years & $23-59$ years \\
\hline Median (IQR) & $55(51-57)$ & $51(45-56)$ & $53(47-57)$ \\
\hline Age groups: $18-24$ & $1(1 \%)$ & 0 & $1(.5 \%)$ \\
\hline $25-29$ & 0 & $1(1 \%)$ & $1(.5 \%)$ \\
\hline $30-34$ & $3(3 \%)$ & $3(2 \%)$ & $6(3 \%)$ \\
\hline $35-39$ & $1(1 \%)$ & $11(9 \%)$ & $12(6 \%)$ \\
\hline $40-44$ & $2(2 \%)$ & $15(11 \%)$ & $17(8 \%)$ \\
\hline $45-49$ & $11(12 \%)$ & $22(17 \%)$ & $33(15 \%)$ \\
\hline $50-54$ & $26(29 \%)$ & $30(24 \%)$ & $56(26 \%)$ \\
\hline $55-59$ & $47(52 \%)$ & $45(35 \%)$ & $92(42 \%)$ \\
\hline Occupation & Women $n=88$ & Men $n=124$ & Total $n=212$ \\
\hline Employed (full/part-time, self-employed) & $47(53 \%)$ & $72(58 \%)$ & $119(56 \%)$ \\
\hline On sick leave & $9(10 \%)$ & $3(2 \%)$ & $12(6 \%)$ \\
\hline Early retirement/disability pension & $22(25 \%)$ & $34(27 \%)$ & $56(26 \%)$ \\
\hline Unemployed (less than 3 years) & $3(3 \%)$ & $5(4 \%)$ & $8(4 \%)$ \\
\hline Unemployed (more than 3 years) & $7(8 \%)$ & $7(6 \%)$ & $14(7 \%)$ \\
\hline Does not work (other reason) & 0 & $3(2 \%)$ & $3(1 \%)$ \\
\hline Household circumstances & Women $n=90$ & Men $n=125$ & Total $n=215$ \\
\hline Living alone & $34(38 \%)$ & $45(36 \%)$ & $79(37 \%)$ \\
\hline Living with someone else & $54(60 \%)$ & $70(56 \%)$ & $124(58 \%)$ \\
\hline Lives at institution & $2(2 \%)$ & $10(8 \%)$ & $12(5 \%)$ \\
\hline Body mass index $\left(\mathrm{kg} / \mathrm{m}^{2}\right)$ & Women $n=91$ & Men $n=121$ & Total $n=212$ \\
\hline Mean (SD) & $22.96( \pm 4.62)$ & $24.08( \pm 3.85)$ & $23.6( \pm 4.2)$ \\
\hline Min-max & $13.6-36.1$ & $13.9-35.8$ & $13.6-36.1$ \\
\hline \multicolumn{4}{|l|}{ BMI distribution: } \\
\hline Underweight $(<18.5)$ & $15(17 \%)$ & $6(5 \%)$ & $21(10 \%)$ \\
\hline Normal (18.5-24.99) & $42(46 \%)$ & $73(60 \%)$ & $115(54 \%)$ \\
\hline Overweight (25.0-29.99) & $28(31 \%)$ & $37(31 \%)$ & $65(31 \%)$ \\
\hline Obese $(>30.00)$ & $6(7 \%)$ & $5(4 \%)$ & $11(5 \%)$ \\
\hline Trauma mechanism & Women $n=91$ & Men $n=127$ & Total $n=218$ \\
\hline Low-energy trauma & $71(78 \%)$ & $77(61 \%)$ & $148(68 \%)$ \\
\hline Not low-energy trauma & $20(22 \%)$ & $50(39 \%)$ & $70(32 \%)$ \\
\hline Fracture type & Women $n=91$ & Men $n=127$ & Total $n=218$ \\
\hline Intracapsular fracture & $55(60 \%)$ & $71(56 \%)$ & $126(58 \%)$ \\
\hline Extracapsular fracture & $36(40 \%)$ & $56(44 \%)$ & $92(42 \%)$ \\
\hline
\end{tabular}

were slightly more common than extracapsular ones (Table 1). No patients were diagnosed with an atypical femur fracture.

\section{Lifestyle factors}

Ninety-two percent of the patients reported no specific dietary preferences (Table 2). Regarding physical activity, less than half of the patients reached a BHW-PA score of 11, i.e. a recommended physical activity level of $150 \mathrm{~min} /$ week, and hand grip strength showed a wide range, $4.5-80.0 \mathrm{~kg}$. Smokers accounted for $42 \%$ of the patients and $16 \%$ were previous smokers. AUDIT results ranged from minimum to maximum score and 19 women $(25 \%)$ and 37 men $(31 \%)$ reported a hazardous or harmful alcohol use. DUDIT results ranged from 0 to 36 points and 4 women (5\%) and 11 men $(10 \%)$ report signs of drug-related problems.

\section{Medical history}

A history of previous disease was common; in all, 313 diseases, both potentially hip fracture associated and other diseases, were found in 144 patients (66\%) (Table 3). A total of 105 patients $(48 \%)$ presented 188 diseases potentially associated with hip fracture and any other disease(s) were present in 98 patients (45\%). Women presented a larger proportion than men of both potentially hip fracture associated 
Table 2 Lifestyle factors

\begin{tabular}{|c|c|c|c|}
\hline Diet & Women $n=82$ & Men $n=121$ & Total $n=203$ \\
\hline Regular diet & $78(95 \%)$ & $108(89 \%)$ & $186(92 \%)$ \\
\hline Vegetarian/vegan & $3(4 \%)$ & $3(2 \%)$ & $6(3 \%)$ \\
\hline Diabetes diet & 0 & $7(6 \%)$ & $7(3 \%)$ \\
\hline Other $^{\mathrm{a}}$ & $1(1 \%)$ & $3(3 \%)$ & $4(2 \%)$ \\
\hline Physical activity level ${ }^{\mathrm{b}}$ & Women $n=85$ & Men $n=122$ & Total $n=207$ \\
\hline Median score (IQR) & $9(6-13)$ & $9(5-17)$ & $9(6-15)$ \\
\hline Physical activity level score $\geq 11$ & $30(35 \%)$ & $54(44 \%)$ & $84(41 \%)$ \\
\hline Hand grip strength (kg) & Women $n=76$ & Men $n=116$ & Total $n=192$ \\
\hline Min-max & $7.1-42.0$ & $4.5-80.0$ & $4.5-80.0$ \\
\hline Mean (SD) & $28.1(7.2)$ & $46.1(13.8)$ & $39.0(14.6)$ \\
\hline Smoking & Women $n=88$ & Men $n=125$ & Total $n=213$ \\
\hline Never regular smoking & $33(38 \%)$ & $57(46 \%)$ & $90(42 \%)$ \\
\hline Previous smoker (quit > 2 years ago) & $16(18 \%)$ & $18(14 \%)$ & $34(16 \%)$ \\
\hline Current smoker (or quit $<2$ years ago) & $39(44 \%)$ & $50(40 \%)$ & $89(42 \%)$ \\
\hline Pack years: & Women $n=52$ & Men $n=58$ & Total $n=110$ \\
\hline Pack years min-max & $0.3-70$ & $0.9-107.5$ & $0.3-107.5$ \\
\hline Pack years median (IQR) & $25.4(14.3-38.8)$ & $30(15-42.4)$ & $29.3(15-40)$ \\
\hline AUDIT $^{c}$ & Women $n=76$ & Men $n=118$ & Total $n=194$ \\
\hline Hazardous or harmful alcohol use: & $19(25 \%)$ & $37(31 \%)$ & $56(29 \%)$ \\
\hline AUDIT min-max & $0-40$ & $0-36$ & $0-40$ \\
\hline AUDIT median (IQR) & $4(1-5.75)$ & $5(3-9)$ & $4(2-8)$ \\
\hline DUDIT $^{\mathrm{d}}$ & Women $n=79$ & Men $n=111$ & Total $n=190$ \\
\hline Signs of drug-related problems: & $4(5 \%)$ & $11(10 \%)$ & $15(8 \%)$ \\
\hline DUDIT min-max & $0-8$ & $0-36$ & $0-36$ \\
\hline DUDIT median (IQR) & $0(0-0)$ & $0(0-0)$ & $0(0-0)$ \\
\hline
\end{tabular}

${ }^{a}$ Muslim, milk and cheese free, gluten free, phosphate reduced kidney diet

${ }^{\mathbf{b}}$ The Swedish Board of Health and Welfare physical activity questions (BHW-PA), a score of 11 and above fulfils WHO recommendations

${ }^{\mathbf{c}}$ AUDIT Alcohol Use Disorders Identification Test

${ }^{\mathbf{d}}$ DUDIT Drug Use Disorders Identification Test

and other diseases $(p=0.025)$. The number of patients with multiple comorbidities is presented in Table 3. Specific diseases potentially associated with increased risk of hip fracture are presented in Appendix Table 6; neurological disease, diabetes, psychiatric disease and disability, osteoporosis, and chronic obstructive pulmonary disease were the most ubiquitous, accounting for $59 \%$ of the diseases.

Two-thirds of the patients were classified as ASA I or II, i.e. none or mild systemic disease, and the remaining patients were classified as ASA III-IV (Table 3). Half of the patients had a history of any previous fracture and 5\% reported a previous hip fracture. In total, $17 \%$ of the cohort reported a family history of fragility fractures.

\section{Previous medication}

During the 5 years preceding the hip fracture, 135 patients (62\%) had used any regular medication and 70 patients
(32\%) had a total of 130 pharmacological treatments from medication groups potentially associated with increased fracture risk (Appendix Table 7). The most common treatments were proton pump inhibitors, selective serotonin reuptake inhibitors and opioids, together they accounted for $40 \%$ of the potentially hip fracture associated treatments.

\section{Blood sample results}

Blood samples were drawn on mean 1.4 (SD 1.1) days preoperative and mean 2.04 (2.4) days post-operative. Results below reference in more than a quarter of the post-operative samples were found for calcium (29\%), albumin (45\%), vita$\min \mathrm{D}(52 \%)$, testosterone (60\%) in men, and estradiol (85\%) in women (Appendix Table 8). Of the pre-operative blood samples, leucocytes and CRP were above reference in $75 \%$ and $30 \%$, and hemoglobin was below reference in $37 \%$ of the samples. 
Table 3 Medical history

\begin{tabular}{|c|c|c|c|}
\hline & Women $n=91$ & Men $n=127$ & Total $n=218$ \\
\hline Any previous disease & $65(71 \%)$ & $79(62 \%)$ & $144(66 \%)$ \\
\hline $\begin{array}{l}\text { Patients with specific disease(s) potentially } \\
\text { associated with hip fracture }^{\mathrm{a}}\end{array}$ & $52(57 \%)$ & $53(42 \%)$ & $105(48 \%)$ \\
\hline Patients with any other disease(s) & $49(54 \%)$ & $49(39 \%)$ & $98(45 \%)$ \\
\hline $\begin{array}{l}\text { Comorbidity (potentially hip fracture asso- } \\
\text { ciated and other diseases) }\end{array}$ & Women $n=91$ & Men $n=127$ & Total $n=218$ \\
\hline No previous disease & $26(29 \%)$ & $48(38 \%)$ & $74(34 \%)$ \\
\hline 1 comorbidity & $25(28 \%)$ & $43(34 \%)$ & $68(31 \%)$ \\
\hline 2 comorbidities & $12(13 \%)$ & $20(16 \%)$ & $32(15 \%)$ \\
\hline 3 comorbidities & $10(11 \%)$ & $10(8 \%)$ & $20(9 \%)$ \\
\hline 4 comorbidities & $8(9 \%)$ & $3(2 \%)$ & $11(5 \%)$ \\
\hline 5 comorbidities & $6(7 \%)$ & $1(1 \%)$ & $7(3 \%)$ \\
\hline 6 comorbidities & $1(1 \%)$ & $1(1 \%)$ & $2(1 \%)$ \\
\hline 7 comorbidities & $1(1 \%)$ & $1(1 \%)$ & $2(1 \%)$ \\
\hline 8 comorbidities & $2(2 \%)$ & 0 & $2(1 \%)$ \\
\hline ASA classification & Women $n=91$ & Men $n=127$ & Total $n=218$ \\
\hline ASA I & $16(18 \%)$ & $44(35 \%)$ & $60(28 \%)$ \\
\hline ASA II & $42(46 \%)$ & $44(35 \%)$ & $86(39 \%)$ \\
\hline ASA III & $31(34 \%)$ & $35(28 \%)$ & $66(30 \%)$ \\
\hline ASA IV & $2(2 \%)$ & $4(3 \%)$ & $6(3 \%)$ \\
\hline Hospital admission & Women $n=90$ & Men $n=124$ & Total $n=214$ \\
\hline Hospital admission within last year & $24(27 \%)$ & $27(22 \%)$ & $51(24 \%)$ \\
\hline Previous hip fracture & Women $n=90$ & Men $n=124$ & Total $n=214$ \\
\hline Yes, contralateral & $3(3 \%)$ & $6(5 \%)$ & $9(4 \%)$ \\
\hline Yes, ipsilateral & 0 & $1(1 \%)$ & $1(.5 \%)$ \\
\hline Previous fracture (after 20 years of age) & Women $n=87$ & Men $n=121$ & Total $n=208$ \\
\hline Previous other fracture & $44(51 \%)$ & $53(44 \%)$ & $97(47 \%)$ \\
\hline Fragility fracture in the family & Women $n=86$ & Men $n=123$ & Total $n=209$ \\
\hline Yes & $21(24 \%)$ & $14(11 \%)$ & $35(17 \%)$ \\
\hline No & $49(57 \%)$ & $82(67 \%)$ & $131(63 \%)$ \\
\hline Do not know & $16(19 \%)$ & $27(22 \%)$ & $43(21 \%)$ \\
\hline
\end{tabular}

${ }^{a}$ Specific diseases potentially associated with hip fracture are specified in Appendix Table 5

\section{DXA results}

A total of 184 patients' DXA scan results were included in the analysis. They were aged 28-59 years, the median was 53 (IQR 47-57) years, compared to a median age of 55 (48-57) for the 26 patients not attending DXA and the 8 patients examined by DXA $>3$ months post-fracture who were excluded from the analysis. Median time to DXA investigation from hip fracture surgery was $5(-324)$ days, $85 \%$ of the analyzed patients had DXA scans within 1 month. $\mathrm{T}$-scores at the lumbar spine, total hip, and femoral neck were normal in $12 \%$, osteopenic in $57 \%$, and osteoporotic in $31 \%$ of the patients. The distribution was similar, with no statistically significant differences between women and men or between low-energy and not low-energy trauma mechanisms, but with a tendency of marginally better DXA results among patients with higher than low-energy trauma mechanism (Table 4). In the youngest age groups, none of the patients had normal DXA results. Normal DXA was firstly seen in age group 40-44 and the highest proportion of normal results was found in age group 45-49 (27\% normal).

Mean T-scores at the femoral neck and total hip in our cohort were lower in all age groups for both women and men compared to NHANES III data (Fig. 2). NHANES III mean T-scores were all normal $(\geq-1)$, but our cohort's mean T-scores were categorized as osteopenia $(<-1$ to $>-2.5)$ in all age groups. Mean T-scores for men from our cohort were lower with increasing age, as NHANES III mean T-scores for both men and women were. In contrast, mean T-scores in women from our cohort were higher with increasing age, both at the femoral neck and total hip.

Patient characteristics according to DXA result for 184 patients assessed by DXA are presented by sex in Appendix Table 9. Smoking, lower BMI, a family history of a fragility fracture, and low vitamin $\mathrm{D}$ were more frequent 
Table 4 DXA diagnosis by sex, age group, and trauma mechanism

\begin{tabular}{llll}
\hline & $\begin{array}{l}\text { Normal } \\
\text { T-score } \geq-1\end{array}$ & $\begin{array}{l}\text { Osteopenia } \\
\text { T-score }-2.5 \text { to }-1\end{array}$ & $\begin{array}{l}\text { Osteoporosis } \\
\text { T-score } \leq-2.5\end{array}$ \\
\hline Sex & & & \\
Women $n=76$ & $9(12 \%)$ & $41(54 \%)$ & $26(34 \%)$ \\
Men $n=108$ & $13(12 \%)$ & $64(60 \%)$ & $31(29 \%)$ \\
Age groups & & & \\
$25-29 n=1$ & 0 & $1(100 \%)$ & 0 \\
$30-34 n=6$ & 0 & $4(67 \%)$ & $2(33 \%)$ \\
$35-39 n=11$ & 0 & $10(91 \%)$ & $1(9 \%)$ \\
$40-44 n=15$ & $2(13 \%)$ & $8(53 \%)$ & $5(33 \%)$ \\
$45-49 n=26$ & $7(27 \%)$ & $13(50 \%)$ & $6(23 \%)$ \\
$50-54 n=51$ & $3(6 \%)$ & $31(61 \%)$ & $26(35 \%)$ \\
$55-59 n=74$ & $10(14 \%)$ & $38(51 \%)$ & $43(36 \%)$ \\
Trauma mechanism & & & $14(22 \%)$ \\
Low-energy trauma $n=120$ & $12(10 \%)$ & $65(54 \%)$ & \\
Not low-energy trauma $n=64$ & $10(16 \%)$ & $40(63 \%)$ & $57(31 \%)$ \\
Total & & & $105(57 \%)$ \\
$n=184$ & $22(12 \%)$ & &
\end{tabular}

Diagnosis based on the lowest T-score on the lumbar spine, femoral neck, or total hip DXA investigation performed at the time of the fracture. Low-energy trauma was defined as a fall from standing or seated position, and any higher degree of trauma energy was classified as not low-energy trauma

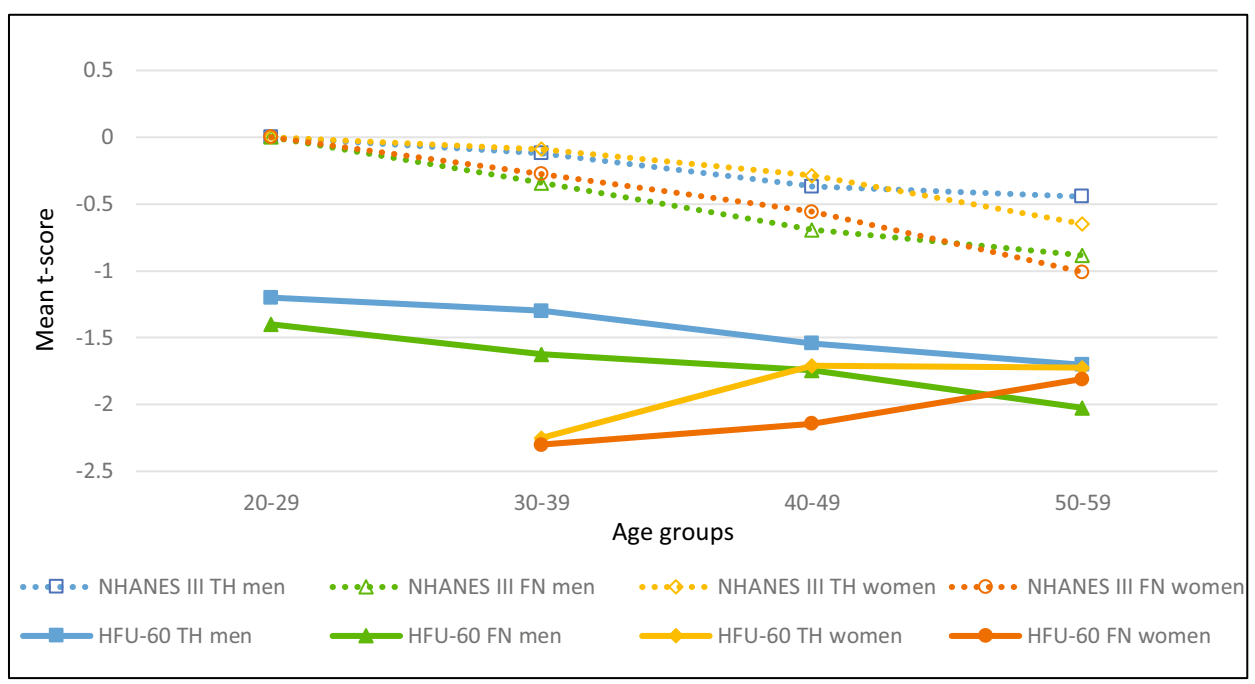

Fig. 2 Comparison of mean T-score by age group, HFU-60 vs. NHANES III. Multiple line chart of HFU-60 mean T-scores for women and men compared to NHANES III mean T-scores calculated from BMD data [25]. TH total hip, FN femoral neck. NHANES III mean BMD data for age groups were converted to T-scores using the formula: $\mathrm{T}$-score $=($ measured BMD - young adult mean BMD $)$ / young adult population SD [23]. Mean T-scores for HFU-60 were significantly lower than NHANES III regarding both TH and FN for men $(p=<.001)$, TH for women $(p=.020)$, and FN for women $(p=.027)$ 
in both women and men with low DXA results. Previous disease, previous fracture, and a higher number of comorbidities were more common in women with low DXA. For men with low DXA, a higher AUDIT score and hip fracture due to low-energy trauma were more frequent.

\section{Discussion}

In the present study on patients with hip fractures under 60 years of age, we found several risk factors for osteoporosis and fractures in our study cohort, and also a high prevalence of osteopenia and osteoporosis upon DXA investigation at the time of the hip fracture.

\section{Demographics}

In contrast to hip fractures in the elderly, it has been shown before that the younger the patients, the larger the proportion of men is $[3,7,9,11]$. Accordingly, $58 \%$ of our cohort were men. The explanation is probably a combination of multiple reasons resulting in young men being at higher risk of fractures than young women; in our cohort, the men presented heavier smoking, more alcohol and drug use, and more fractures due to a higher than low-energy trauma mechanism suggesting a more risk-taking behaviour in men.

The fact that only half of the participants were working, compared to four-fifths among the general population 20 to 64 years of age in Denmark and Sweden[27], reflects a socioeconomic distress known to be associated with an increased fracture risk [28].

\section{The injury}

Two-thirds of the hip fractures in our cohort were related to low-energy trauma, i.e. a fall from standing or a seated position, in contrast to the preconception that hip fractures in younger patients are caused mainly by high-energy trauma. Previous studies present large variations in trauma mechanisms, depending on inclusion criteria and settings. Studies on general hip fracture populations like ours support our finding that low-energy trauma was the cause for a majority of the fractures $[1,9,10]$.

No patients were diagnosed with an atypical femur fracture; considering the previously reported low incidence of 1.74 fractures per 10000 patient-years [29] and that only 7 patients used bisphosphonates, no atypical femur fractures were expected in the cohort.

\section{Lifestyle factors}

The physical activity level in our cohort was lower than a Swedish random population sample measured by the same questionnaire [15]. More than half of our study participants had a lower physical activity level than the recommended minimum according to the WHO of 150 min per week [17]. In contrast, $72 \%$ of the general population in Denmark and $66 \%$ in Sweden reach the recommended minimum physical activity level [30, 31].

On hand grip strength measurement, $57 \%$ of the women and $58 \%$ of the men had results lower than the mean from a random population sample of Danish women and men aged 19 to 72 years [18]. Considering that the hand grip strength was lower with increasing age in the general population, our younger cohort performed markedly lower results than the general population of comparable ages.

Smoking was 2.5 to 3.8 times as common in the study cohort than in the general population, where $17 \%$ smoke in Denmark and $11 \%$ in Sweden $[32,33]$. The rate of smokers was also higher than in most other young hip fracture cohorts [1, 2, 34] but on par with Al-Ani et al. [12].

Among our study participants, harmful use of alcohol and drug-related problems were much more common than what is reported from the general population in the countries. One quarter of the women had a harmful alcohol consumption, and the Swedish average is suggested to be $11 \%$ [19]. The corresponding number for men was $31 \%$ in the study, and population data suggest 18 to $23 \%$ in Sweden and Denmark $[19,35]$. In other observational studies, the presence of alcohol use disorder varies from 15 to $38 \%$ [2, 9, 10, 36, 37]. A cohort from Scotland, described by Stearns et al., exhibit extreme use of alcohol and tobacco, 47 and $67 \%$, but is characterized as a "largely very deprived population" [38].

On the DUDIT questionnaire, $8 \%$ of the study cohort presented a result indicating a drug-related problem, which is close to 3 times higher than previously reported from the Swedish population [20]. To the best of our knowledge, no earlier studies on patients with hip fractures have used DUDIT to estimate substance use disorder; wherefore, comparison is not possible. Still, the majority of the fracture patients did not have alcohol or substance use disorder, which is otherwise a perfunctory explanation often heard-that younger patients with hip fractures are "addicts". This suggests that 
other associated factors may be present as well in young and middle-aged patients with hip fractures.

\section{Medical history}

In terms of comorbidity, our cohort was divided into thirds, with either none, one, or several comorbidities. The third of the patients with multiple comorbidities carried $78 \%$ of the total disease burden. Previous diseases potentially associated with hip fracture were found in $48 \%$ of the patients. Other studies on young hip fracture patients have noted comorbidities in 9 to $55 \%$, suggesting different types of populations between the studies [7, 10, $36,38-41]$.

\section{Previous medication}

Proton pump inhibitors and selective serotonin reuptake inhibitors were consumed by 9 and $8 \%$ of the patients, respectively. Corticosteroids, a known mediator of poor bone health [13], were used by $5 \%$, and previous studies have reported on 1 to $9 \%[10,42]$.

\section{Blood sample results}

Pathological values for calcium, vitamin $\mathrm{D}$, and albumin were common. This may reflect predisposal for poor bone health and general frailty. Also the findings of low sex hormones could be associated with low BMD, but these tests were taken post-operatively and after opioids were given, which may lower the level of testosterone [43].

\section{DXA results}

Analysis of bone mineral density at the time of the hip fracture showed a high prevalence of osteopenia and osteoporosis, only 1 in 8 had a normal DXA result. Patients with a hip fracture due to a higher than low-energy trauma mechanism had slightly better DXA results, but still only 1 in 6 had a normal T-score. Remarkably, no normal results were found in patients younger than age 40. Mean T-scores for women and men from the HFU-60 cohort were lower than NHANES
III in all age groups and were all categorized as osteopenia. These findings state that bone quality should be suspected to be abnormal in young and middle-aged patients with hip fractures. Furthermore, we were not able to distinguish any subgroups with no or low risk of low bone mass, why all young and middle-aged patients with hip fractures may be considered at risk of low bone mass, and should be investigated accordingly [44].

In comparison, normative DXA data from a populationbased sample of 25-year-old women from Malmö, Sweden, reported a much lower prevalence of osteopenia and osteoporosis [45]. Thus, osteopenia in either femoral neck, total hip, or lumbar spine was seen only in $4.5-9.3 \%$ of the cases and osteoporosis in $0-0.3 \%$.

In a population-based sample of women and men aged 30-60 years, from Troms $\varnothing$, Norway, the prevalence of osteoporosis in femoral neck or total hip is reported to be between 0 and 5\% depending on age and sex, i.e. considerably lower than our findings [46].

That our cohort of patients with hip fractures under the age of 60-regardless of trauma mechanism-have inferior bone health is supported by the similarity between our results and Al-Ani et al., who found osteopenia in 54\% and osteoporosis in 35\% in their somewhat older group with hip fractures from Stockholm, Sweden [12].

\section{Limitations}

Our study has some limitations; the legislation on personal privacy prohibits us to perform a drop-out analysis of eligible patients not included in the study; therefore, we cannot estimate the influence of selection bias.

An upper age limit of 60 years could be considered both too high and too low for a study focusing on non-elderly hip fracture patients. There is no consensus regarding the cut-off between non-elderly and elderly patients; a range from 40 to 70 years have been used in earlier studies $[12,39]$. We chose 60 years as the upper age limit of our cohort, partly due to the clinical guidelines at the department of origin of the study, where 60 years of age has been the divide for arthroplasty, rather than osteosynthesis, as the treatment of choice for displaced femoral neck fractures. The proportion 
of non-elderly individuals of all hip fracture patients is $2-13 \%$ according to previous reports $[4,6]$, the proportion in our material is $6 \%$ which corresponds well considering the variation in age limits in previous studies.

One could argue that there are few very young patients in our cohort, $91 \%$ of the patients are aged 40 to 59 years, but this is coherent with a Danish register study where $90 \%$ of hip fractures in patients under 65 years of age are found in patients aged 40 to 65 [4]. In a Swedish register study on patients with hip fractures younger than 50 years, the median age was 42 [47]. When excluding patients aged 50-59, our cohort show a corresponding median age of 44; hence, we consider our sample sufficiently representative.

\section{Strengths}

We consider our study to have important strengths; three quarters of the eligible cases were included in this multicenter prospective study. The patients were thoroughly investigated regarding demographics, trauma mechanism, lifestyle factors, comorbidity, and medication as well as by blood samples and DXA, providing an extensive description of the patient group. The participating hospitals served both urban and rural catchment areas and provided care for all fracture cases regardless of trauma or patient type. Care given at low or no cost for the patients ensures that no one abstains from seeking hospital care. Thereby, we regard our study population to reflect the entire, heterogenous group of individuals suffering hip fractures in young and middle age. This is in contrast to studies performed at Level I trauma centers or health care systems were socially deprived individuals have little access to hospital care, leading to selection bias [7]. Our results are generalizable to many highincome countries, whilst other parts of the world may face more traffic or occupational injuries and a different case mix $[8,41]$.

We believe that DXA performed at the time of hip fracture in contrast to years after, more accurately describes the pre-fracture condition. Al-Ani et al. [12] have presented similar DXA results adjacent to the fracture, but in a smaller and older patient group. To put our DXA results in relation to normative data, we have compared our findings to reference populations regarding different ages and sex, both internationally used reference data (NHANES III) [25] and locally collected normative DXA result data $[45,46]$. The comparisons support the argument that the bone health of young and middle-aged patients with hip fractures is inferior to what could be expected in the general population of the same ages.

\section{Conclusion}

Our cohort of patients with hip fractures under the age of 60 is heterogenous; the patients present a wide range of demographics and lifestyle factors as well as previous fractures and comorbidities. Based on our findings, young and middle-aged patients with hip fractures show signs of vitality and health, yet primarily_-and more concerning — there is a high degree of frailty and risk factors for osteoporosis and fractures are numerous. We also found a high prevalence of osteopenia and osteoporosis compared to the general population, only one in eight had a normal DXA result.

\section{Clinical perspective}

The majority of the patients had previous medical conditions and abnormal blood sample results as well as inferior bone quality on BMD assessment by DXA. We suggest that all young and middle-aged patients with hip fractures should undergo a thorough health investigation including DXA, a non-invasive and relatively easily accessible procedure that previously have been reported to be performed in only less than half of young patients with hip fractures [1].

The variation in patient characteristics and physical abilities at the time of the hip fracture suggests that these patients have different needs regarding rehabilitation to reach their pre-fracture functional level and demands. Other rehabilitation pathways tailored to the needs of these patients, not only standard geriatric hip fracture rehabilitation, are assumingly needed. This will be analyzed further in future studies within the HFU-60 project. 


\section{Appendix}

Table 5 Definition of recorded variables

\begin{tabular}{|c|c|c|}
\hline Variable & Data source & Method of assessment (measurement) \\
\hline \multicolumn{3}{|l|}{ Demographics } \\
\hline Age & Personal number ${ }^{\mathrm{a}}$ & Age at fracture according to birth date \\
\hline Sex & Personal number ${ }^{\mathrm{a}}$ & Sex as defined by personal number \\
\hline Occupation & Patient interview & Pre-defined category selected by patient \\
\hline Household circumstances & Patient interview & Pre-defined category selected by patient \\
\hline BMI & Patient interview and medical charts & Weight divided by squared length $\left(\mathrm{kg} / \mathrm{m}^{2}\right)$ \\
\hline \multicolumn{3}{|l|}{ The injury } \\
\hline Trauma mechanism & Patient interview and medical charts & Defined as low-energy or not low-energy \\
\hline Fracture type & Radiographs & Classified by orthopaedic surgeon \\
\hline \multicolumn{3}{|l|}{ Lifestyle factors } \\
\hline Smoking & Patient interview & Pre-defined category selected by patient \\
\hline Pack years & Patient interview & Average number of cigarettes/day x years smoking \\
\hline Diet & Patient interview & Pre-defined category selected by patient \\
\hline AUDIT [19] & Patient questionnaire & Score according to questionnaire instructions \\
\hline DUDIT [20] & Patient questionnaire & Score according to questionnaire instructions \\
\hline Physical activity level score (BHW-PA [15]) & Patient interview & Score according to questionnaire instructions \\
\hline Hand grip strength & Functional test by physiotherapist & Measured in $\mathrm{kg}$ by dynamometer \\
\hline \multicolumn{3}{|l|}{ Medical history } \\
\hline Any previous disease & Patient interview and medical charts & Presence of previous disease \\
\hline Potentially hip fracture associated previous disease & Patient interview and medical charts & Presence of pre-specified previous disease \\
\hline Hospital admission within 1 year prior to hip fracture & Patient interview and medical charts & Defined as yes or no \\
\hline ASA classification [14] & Medical charts & Assessed by anesthesiologist \\
\hline Previous hip fracture & Patient interview and medical charts & Defined as yes or no \\
\hline Previous other fracture (after 20 years of age) & Patient interview and medical charts & Defined as yes or no \\
\hline Fragility fracture in first-hand relative & Patient interview and medical charts & Defined as yes or no \\
\hline Previous medication & Patient interview and medical charts & Presence of pre-specified medical treatments \\
\hline Blood sample result & Medical charts & Defined as normal or below/above reference \\
\hline DXA result & DXA investigation & Result defined according to WHO definitions \\
\hline
\end{tabular}

${ }^{a}$ The personal number is a national identification number including information on birth date and sex, unique to every individual, used nationally in both Denmark and Sweden 
Table 6 Specific diseases potentially associated with increased risk of hip fracture

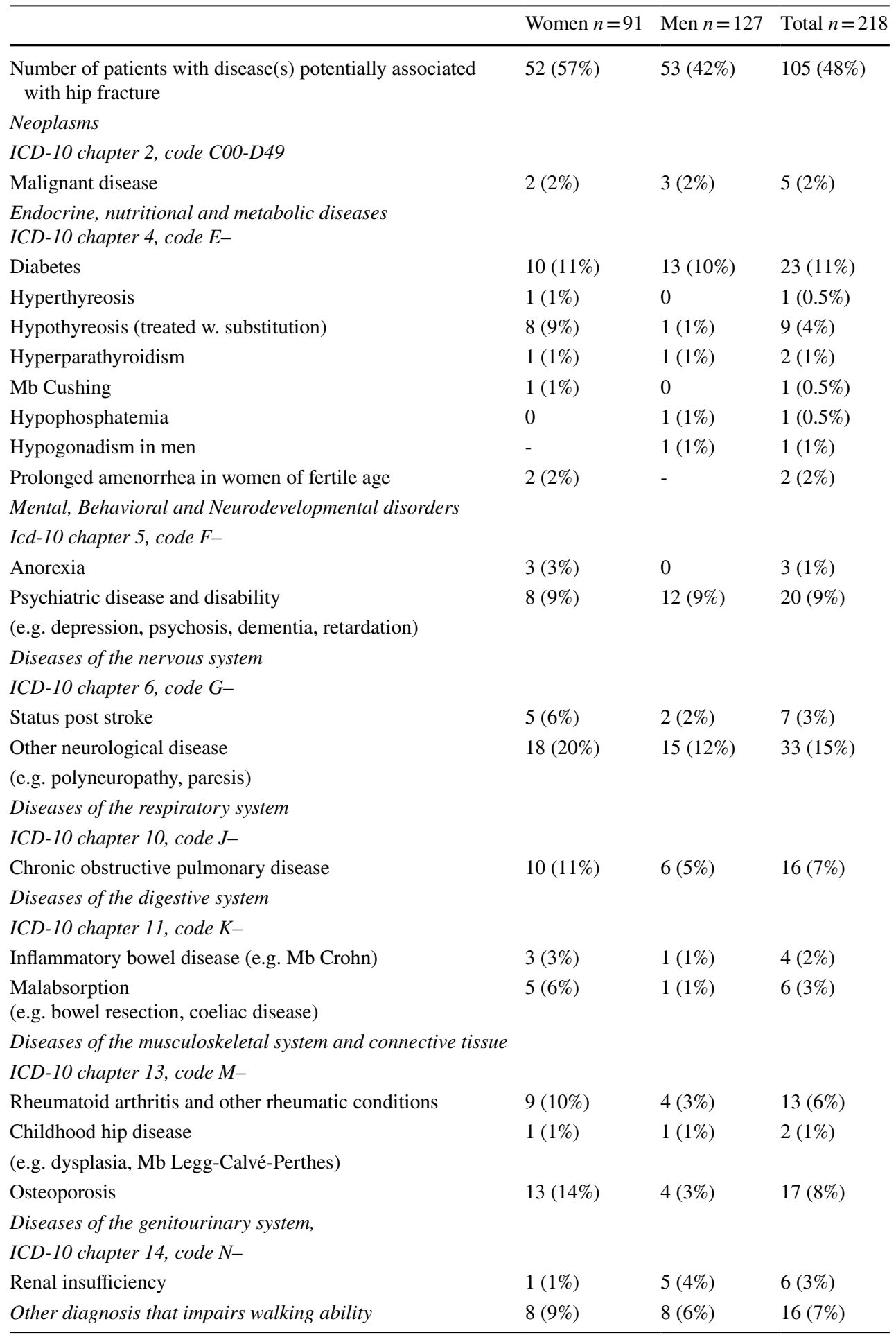


Table 7 Previous potentially hip fracture associated medication

Women $n=91 \quad$ Men $n=127 \quad$ Total $n=218$

Previous use of potentially hip fracture associated medication

$34(37 \%) \quad 36(29 \%) \quad 70(32 \%)$

ATC code $\quad$ Example of use/diagnosis $\quad$ Example of medication name

$\mathrm{A} 02 \mathrm{BC}$

Proton pump inhibitors

Peptic ulcer, gastro-oesophageal reflux disease

N06AB

Selective serotonin reuptake inhibitors

N02A

Opioids

$\mathrm{H} 02 \mathrm{AB}$

Glucocorticoids

B01A

Antithrombotic agents

N03AF

Carboxamide derivates

C03CA

Loop-diuretics

M01A

NSAID

H03AA

Thyroid hormones

M05B

Bisphosphonates

G03

Sex hormones

L01, L04

Antineoplastic and immunomodulating agents

L02BG

Aromatase inhibitors

G03AC06

Progestogens
Antidepressants

Pain

Systemic corticosteroids

Antithrombotic therapy

Antiepileptics

Hypertension, heart failure

RA, osteoarthrosis, pain

Hypothyreosis

Osteoporosis

Hormonal therapy

Cancer, rheumatoid arthritis

Cancer (breast, endometrial, prostatic)

Contraceptive
Omeprazole, pantoprazole, lansoprazole

Citalopram, sertraline, fluoxetine

Morphine, methadone, fentanyl 8 (9\%)

$7(6 \%)$

Prednisolone, betamethasone, $\quad 6(7 \%)$ hydrocortisone

$6(5 \%) \quad 12(6 \%)$

Heparin, dalteparin, warfarin

$4(4 \%)$

$8(6 \%)$

$12(6 \%)$

Carbamazepine, oxcarbazepine, 5 (5\%) rufinamide

$5(4 \%) \quad 10(5 \%)$

Furosemide

$5(5 \%)$

$4(3 \%)$

$9(4 \%)$

Diclofenac, ibuprofen

$4(4 \%)$

$5(4 \%)$

$9(4 \%)$

Levothyroxine, liothyronine

$7(8 \%)$

$1(1 \%)$

$8(4 \%)$

Aledronic acid, zoledronic acid $3(3 \%)$

$4(3 \%)$

$7(3 \%)$

Androgens, estrogens

$3(3 \%)$

$2(2 \%)$

Cyklophosphamide, busulfan,

$2(2 \%)$

$2(2 \%)$

$4(2 \%)$ methotrexate

Anastrozole, letrozole, exemes- $1(1 \%)$

0

$1(0.5 \%)$

tane

Medroxyprogesterone

$1(1 \%)$

$1(0.5 \%)$ 
Table 8 Blood sample results

\begin{tabular}{|c|c|c|c|c|c|c|c|c|}
\hline & \multicolumn{2}{|c|}{ No. of samples } & \multicolumn{2}{|c|}{ Below reference } & \multicolumn{2}{|l|}{ Normal } & \multicolumn{2}{|c|}{ Above reference } \\
\hline & Women & Men & Women & Men & Women & Men & Women & Men \\
\hline \multicolumn{9}{|l|}{ Pre-operative } \\
\hline Hemoglobin & 90 & 127 & $40(44 \%)$ & $41(32 \%)$ & $50(56 \%)$ & $84(66 \%)$ & 0 & $2(2 \%)$ \\
\hline Leucocytes & 89 & 124 & $1(1 \%)$ & 0 & $23(26 \%)$ & $29(23 \%)$ & $65(73 \%)$ & $95(77 \%)$ \\
\hline Platelet count & 72 & 93 & $9(13 \%)$ & $7(8 \%)$ & $57(79 \%)$ & $80(86 \%)$ & $6(8 \%)$ & $6(7 \%)$ \\
\hline CRP & 90 & 124 & N/A & N/A & $72(80 \%)$ & $77(62 \%)$ & $18(20 \%)$ & $47(38 \%)$ \\
\hline Sodium $(\mathrm{Na}+)$ & 90 & 127 & $24(27 \%)$ & $28(22 \%)$ & $63(70 \%)$ & $98(77 \%)$ & $3(3 \%)$ & $1(1 \%)$ \\
\hline Potassium $(\mathrm{K}+)$ & 90 & 127 & $14(16 \%)$ & $11(9 \%)$ & $71(79 \%)$ & $100(79 \%)$ & $5(6 \%)$ & $16(13 \%)$ \\
\hline Creatinine & 89 & 127 & $33(37 \%)$ & $18(14 \%)$ & $52(58 \%)$ & $91(72 \%)$ & $4(5 \%)$ & $18(14 \%)$ \\
\hline INR & 83 & 112 & N/A & N/A & $73(88 \%)$ & $100(89 \%)$ & $10(12 \%)$ & $12(11 \%)$ \\
\hline \multicolumn{9}{|l|}{ Post-operative } \\
\hline Calcium-P & 77 & 112 & $24(31 \%)$ & $31(28 \%)$ & $53(69 \%)$ & $80(71 \%)$ & 0 & $1(1 \%)$ \\
\hline Albumin & 69 & 101 & $40(58 \%)$ & $37(37 \%)$ & $29(42 \%)$ & $64(63 \%)$ & 0 & 0 \\
\hline 25-hydroxyvitamin D & 74 & 104 & $34(46 \%)$ & $59(57 \%)$ & $40(54 \%)$ & $45(43 \%)$ & N/A & N/A \\
\hline Alkaline phosphatase & 84 & 107 & $1(1 \%)$ & $3(3 \%)$ & $68(81 \%)$ & $83(78 \%)$ & $15(18 \%)$ & $21(20 \%)$ \\
\hline PTH & 79 & 114 & 0 & $3(3 \%)$ & $71(90 \%)$ & $96(84 \%)$ & $8(10 \%)$ & $15(13 \%)$ \\
\hline TSH & 77 & 115 & $5(7 \%)$ & 0 & $69(87 \%)$ & $107(93 \%)$ & $3(4 \%)$ & $8(7 \%)$ \\
\hline $\mathrm{T} 3$ & 24 & 26 & $6(25 \%)$ & $1(4 \%)$ & $17(71 \%)$ & $24(92 \%)$ & $1(4 \%)$ & $1(4 \%)$ \\
\hline $\mathrm{T} 4$ & 26 & 33 & 0 & 0 & $26(100 \%)$ & $30(91 \%)$ & 0 & $3(9 \%)$ \\
\hline P-Testosterone & - & 108 & - & $65(60 \%)$ & - & $43(40 \%)$ & - & 0 \\
\hline Estradiol & 72 & - & $61(85 \%)$ & - & $11(15 \%)$ & - & 0 & - \\
\hline Tissue transglutaminase antibody & 75 & 109 & N/A & N/A & $74(99 \%)$ & $109(100 \%)$ & $1(1 \%)$ & 0 \\
\hline
\end{tabular}


Table 9 Patient characteristics according to DXA result, focusing on risk factors for osteoporosis

\begin{tabular}{|c|c|c|c|c|}
\hline & \multicolumn{2}{|l|}{ Women } & \multicolumn{2}{|l|}{ Men } \\
\hline & $\begin{array}{l}\text { Low DXA } \\
\text { T-score }<-1 n=67\end{array}$ & $\begin{array}{l}\text { Normal DXA } \\
\text { T-score } \geq-1 n=9\end{array}$ & $\begin{array}{l}\text { Low DXA } \\
\text { T-score }<-1 n=95\end{array}$ & $\begin{array}{l}\text { Normal DXA } \\
\text { T-score } \geq-1 n=13\end{array}$ \\
\hline Age median (IQR) & $54(51-57)$ & $56(50-58.5)$ & $51(44-56)$ & $49(45-56.5)$ \\
\hline Smoking* & $n=66$ & & $n=94$ & \\
\hline Non-smoker & $24(36 \%)$ & $5(56 \%)$ & $41(44 \%)$ & $9(69 \%)$ \\
\hline Previous smoker & $13(20 \%)$ & $1(11 \%)$ & $13(14 \%)$ & $2(15 \%)$ \\
\hline Current smoker & $29(44 \%)$ & $3(33 \%)$ & $40(43 \%)$ & $2(15 \%)$ \\
\hline Pack years* & $n=40$ & $n=4$ & $n=47$ & $n=4$ \\
\hline Min-max & $0.3-54$ & $6.8-47$ & $0.9-107.5$ & $10-52.5$ \\
\hline Median (IQR) & $25(13-37)$ & $34(11-47)$ & $30(18-44)$ & $26(11-49)$ \\
\hline AUDIT* & $n=58$ & $n=8$ & $n=90$ & \\
\hline High AUDIT & $15(26 \%)$ & $2(25 \%)$ & $28(31 \%)$ & $3(23 \%)$ \\
\hline Min-max & $0-40$ & $0-13$ & $0-36$ & $0-24$ \\
\hline Median (IQR) & $4(1-6)$ & $4.5(1.5-5.8)$ & $5(3-9)$ & $3(0.5-7.5)$ \\
\hline DUDIT* & $n=61$ & $n=7$ & $n=83$ & $n=12$ \\
\hline High DUDIT & $3(5 \%)$ & $1(14 \%)$ & $10(12 \%)$ & 0 \\
\hline Min-max & $0-5$ & $0-8$ & $0-36$ & $0-0$ \\
\hline BMI* & & & $n=91$ & \\
\hline Min-max & $16.7-33.9$ & $23.1-36$ & $15.8-35.8$ & $21.7-34.6$ \\
\hline Mean (SD) & $22.8(4)$ & $28.4(4.4)$ & $24.1(3.7)$ & $26.4(3.3)$ \\
\hline \multicolumn{5}{|l|}{ Trauma mechanism } \\
\hline Low-energy trauma & $50(75 \%)$ & $7(78 \%)$ & $58(61 \%)$ & $5(39 \%)$ \\
\hline Not low-energy trauma & $17(25 \%)$ & $2(22 \%)$ & $37(39 \%)$ & $8(62 \%)$ \\
\hline Any disease & $47(70 \%)$ & $5(56 \%)$ & $56(59 \%)$ & $11(85 \%)$ \\
\hline Potentially hip fracture associated disease & $40(60 \%)$ & $2(22 \%)$ & $37(39 \%)$ & $6(46 \%)$ \\
\hline Other disease(s) & $34(51 \%)$ & $4(44 \%)$ & $34(36 \%)$ & $8(62 \%)$ \\
\hline Hospital admission within last year* & $16(24 \%)$ & $2(22 \%)$ & $19(20 \%) n=94$ & $4(31 \%)$ \\
\hline \multicolumn{5}{|l|}{ ASA classification } \\
\hline Mean (SD) & $2.09(0.71)$ & $2.11(0.93)$ & $1.95(0.86)$ & $1.85(0.69)$ \\
\hline ASA I & $14(21 \%)$ & $2(22 \%)$ & $35(37 \%)$ & $4(31 \%)$ \\
\hline ASA II & $33(49 \%)$ & $5(56 \%)$ & $32(34 \%)$ & $7(54 \%)$ \\
\hline ASA III & $20(30 \%)$ & $1(11 \%)$ & $26(27 \%)$ & $2(15 \%)$ \\
\hline ASA IV & 0 & $1(11 \%)$ & $2(2 \%)$ & 0 \\
\hline \multicolumn{5}{|l|}{ Comorbidity calculation } \\
\hline Min-max & $0-7$ & $0-7$ & $0-7$ & $0-5$ \\
\hline Mean (SD) & $1.82(1.8)$ & $1.33(2.3)$ & $1.09(1.3)$ & $1.69(1.4)$ \\
\hline Any previous fracture* & $34(51 \%)$ & $2(22 \%)$ & $37(40 \%) n=93$ & $11(85 \%)$ \\
\hline Fragility fracture in the family* & $19(30 \%) n=64$ & $1(11 \%)$ & $13(14 \%) n=92$ & 0 \\
\hline $\begin{array}{l}\text { Previous potentially hip fracture associated } \\
\text { medication }\end{array}$ & $26(39 \%)$ & $3(33 \%)$ & $28(30 \%)$ & $4(31 \%)$ \\
\hline \multicolumn{5}{|l|}{ Blood samples below reference* } \\
\hline Calcium & $18(31 \%) n=59$ & $2(29 \%) n=7$ & $23(26 \%) n=86$ & $4(36 \%) n=11$ \\
\hline Albumin & $29(55 \%) n=53$ & $4(67 \%) n=6$ & $26(34 \%) n=76$ & $4(44 \%) n=9$ \\
\hline Vitamin D & $26(46 \%) n=56$ & $1(17 \%) n=6$ & $46(59 \%) n=78$ & $4(36 \%) n=11$ \\
\hline Testosterone & - & - & $47(57 \%) n=82$ & $9(75 \%) n=12$ \\
\hline Estradiol & $46(85 \%) n=54$ & $5(71 \%) n=7$ & - & - \\
\hline
\end{tabular}

*Variables with missing data, the number of observations for each variable is indicated for each cell with missing data 
Acknowledgements During this work, we received help and support from people outside the author group, thank you all. We would like to mention the local DXA units for their help, with the investigation of patients and also when the first author visited with the phantom. Thank you to our local assistants for your help and administrative support, especially project coordinator Marika Hell in Malmö, Anne Jess Hansen in Kolding, and project nurse Annie Gam-Pedersen in Odense. We would also like to acknowledge the work of the staff at the local wards and out-patient clinics where our patients were treated, and specifically the physiotherapists who performed the functional assessments. Thanks as well for the use of REDCap as part of OPEN, Open Patient data Explorative Network, Odense University Hospital, Region of Southern Denmark.

Funding Open access funding provided by Lund University. This work was supported by grants from Greta and Johan Kock Foundation, A. Påhlsson Foundation, H Järnhardt foundation, Skåne University Hospital Research Fund, the Research and Development Council of Region Skåne, the Swedish Research Council funding for clinical research in medicine, and "Region Syddanmarks forskningsfond" from the Region of Southern Denmark. None of the funders had influence on the scientific work of this study.

Data availability The data that support the findings of this study are available on request from the corresponding author. The data are not publicly available due to privacy or ethical restrictions.

Declarations None of the authors has potential conflicts of interest related to the study. Unrelated to the study, the authors have the following potential conflicts of interest to disclose:

Bjarke Viberg: paid lectures from Osmedic, Swemac and Zimmer Biomet.

Jens-Erik Beck Jensen: advisory boards Amgen, Eli Lilly, UCB, Gedion Richter. Speakers bureau Amgen, UCB, Utsuka. Grants Eli Lilly, Amgen.

Kristina E Akesson: advisory boards Amgen, Astellas Pharma, FAN Network, UCB. Speakers bureau Amgen, Astellas Pharma, Chugai, UCB.

Sebastian Strøm Rönnquist, Morten Tange Kristensen, Henrik Palm, Carsten Fladmose Madsen, Søren Overgaard, Cecilia Rogmark: nothing to declare.

Open Access This article is licensed under a Creative Commons Attribution-NonCommercial 4.0 International License, which permits any non-commercial use, sharing, adaptation, distribution and reproduction in any medium or format, as long as you give appropriate credit to the original author(s) and the source, provide a link to the Creative Commons licence, and indicate if changes were made. The images or other third party material in this article are included in the article's Creative Commons licence, unless indicated otherwise in a credit line to the material. If material is not included in the article's Creative Commons licence and your intended use is not permitted by statutory regulation or exceeds the permitted use, you will need to obtain permission directly from the copyright holder. To view a copy of this licence, visit http://creativecommons.org/licenses/by-nc/4.0/.

\section{References}

1. Wang MT, Yao SH, Wong P et al (2017) Hip fractures in young adults: a retrospective cross-sectional study of characteristics, injury mechanism, risk factors, complications and follow-up. Arch Osteoporos 12:46. https://doi.org/10.1007/s11657-017-0339-y
2. Karantana A, Boulton C, Bouliotis G, et al. (May) Epidemiology and outcome of fracture of the hip in women aged 65 years and under: a cohort study. J Bone Jt Surg Br 93:658-64. 93-B/5/658 [pii] https://doi.org/10.1302/0301-620X.93B5.24536

3. Robinson CM, Court-Brown CM, McQueen MM, Christie J (1995) Hip fractures in adults younger than 50 years of age. Epidemiology and results. Clin Orthop Relat Res 238-46

4. Omari A, Madsen CM, Lauritzen JB et al (2019) Comorbidity and mortality after hip fracture in nineteen thousand six hundred and eighty two patients aged eighteen to sixty five years in Denmark from 1996 to 2012. Int Orthop. https://doi.org/10.1007/ s00264-019-04323-z

5. Cheng K, Montgomery S, Housley S, Wheelwright E (2009) Clinical risk factors for hip fracture in young adults under 50 years old. Eur J Trauma Emerg Surg 35:40-42. https://doi.org/ 10.1007/s00068-008-7177-y

6. Rogmark C, Kristensen MT, Viberg B et al (2018) Hip fractures in the non-elderly — who, why and whither? Injury 49:1445-1450. https://doi.org/10.1016/j.injury.2018.06.028

7. Swiontkowski MF, Winquist RA, Hansen ST (1984) Fractures of the femoral neck in patients between the ages of twelve and fortynine years. J Bone Jt Surg Am 66:837-846

8. Gupta M, Arya R-K, Kumar S et al (2016) Comparative study of multiple cancellous screws versus sliding hip screws in femoral neck fractures of young adults. Chin J Traumatol Zhonghua Chuang Shang Za Zhi 19:209-212. https://doi.org/10.1016/j.cjtee. 2015.11.021

9. Lofthus CM, Osnes EK, Meyer HE et al (2006) Young patients with hip fracture: a population-based study of bone mass and risk factors for osteoporosis. Osteoporos Int 17:1666-1672. https:// doi.org/10.1007/s00198-006-0176-0

10. Al-Ani AN, Neander G, Samuelsson B et al (2013) Risk factors for osteoporosis are common in young and middle-aged patients with femoral neck fractures regardless of trauma mechanism. Acta Orthop 84:54-59. https://doi.org/10.3109/17453674.2013.765639

11. Boden SD, Labropoulos P, Saunders R (1990) Hip fractures in young patients: is this early osteoporosis? Calcif Tissue Int 46:6572. https://doi.org/10.1007/BF02556089

12. Al-Ani AN, Cederholm T, Sääf M et al (2015) Low bone mineral density and fat-free mass in younger patients with a femoral neck fracture. Eur J Clin Invest 45:800-806. https://doi.org/10.1111/ eci. 12472

13. Kanis JA (2002) Diagnosis of osteoporosis and assessment of fracture risk. THE LANCET 359:8

14. ASA Physical Status Classification System. https://www.asahq. org/standards-and-guidelines/asa-physical-status-classificationsystem. Accessed 3 Feb 2021

15. Olsson SJG, Ekblom Ö, Andersson E et al (2016) Categorical answer modes provide superior validity to open answers when asking for level of physical activity: a cross-sectional study. Scand J Public Health 44:70-76. https://doi.org/10.1177/1403494815 602830

16. Kallings L Validering av Socialstyrelsens Screeningfrågor om Fysisk Aktivitet. GIH - The Swedish School of Sport and Health Sciences. https://www.socialstyrelsen.se/globalassets/sharepointdokument/dokument-webb/nationella-riktlinjer/levnadsvanorvalidering-av-indikatorfragor-till-patienter-om-fysisk-aktivitet. pdf. Accessed 5 Dec 2020

17. World Health Organization (2020) WHO guidelines on physical activity and sedentary behaviour. https://apps.who.int/iris/handle/ 10665/336656. Accessed 31 Jan 2021

18. Aadahl M, Beyer N, Linneberg A et al (2011) Grip strength and lower limb extension power in 19-72-year-old Danish men and women: the Health 2006 study. BMJ Open 1:e000192. https://doi. org/10.1136/bmjopen-2011-000192 
19. Bergman H (2002) Alcohol use among Swedes and a psychometric evaluation of the Alcohol Use Disorders Identification Test. Alcohol Alcohol 37:245-251. https://doi.org/10.1093/alcalc/37.3. 245

20. Berman AH, Bergman H, Palmstierna T, Schlyter F (2005) Evaluation of the Drug Use Disorders Identification Test (DUDIT) in criminal justice and detoxification settings and in a Swedish population sample. Eur Addict Res 11:22-31. https://doi.org/10.1159/ 000081413

21. Saunders JB, Aasland OG, Babor TF et al (1993) Development of the alcohol use disorders identification test (AUDIT): WHO collaborative project on early detection of persons with harmful alcohol consumption-II. Addiction 88:791-804. https://doi.org/ 10.1111/j.1360-0443.1993.tb02093.x

22. For the IOF Committee of Scientific Advisors Working Group on Osteoporosis Pathophysiology, Ferrari S, Bianchi ML et al (2012) Osteoporosis in young adults: pathophysiology, diagnosis, and management. Osteoporos Int 23:2735-2748. https://doi.org/10. 1007/s00198-012-2030-x

23. Blake GM, Fogelman I (2007) The role of DXA bone density scans in the diagnosis and treatment of osteoporosis. Postgrad Med J 83:509-517. https://doi.org/10.1136/pgmj.2007.057505

24. Karlsson M, Nilsson JA, Sernbo I et al (1996) Changes of bone mineral mass and soft tissue composition after hip fracture. Bone 18:19-22. https://doi.org/10.1016/8756-3282(95)00422-X

25. Looker AC, Wahner HW, Dunn WL et al (1998) Updated data on proximal femur bone mineral levels of US adults. Osteoporos Int 8:468-490. https://doi.org/10.1007/s001980050093

26. Hanson J (1997) Standardization of femur BMD. J Bone Miner Res 12:1316-1317. https://doi.org/10.1359/jbmr.1997.12.8. 1316

27. Statistics I Eurostat. https://ec.europa.eu/eurostat/databrowser/ view/t2020_10/default/table?lang=en. Accessed 14 Jul 2021

28. Stenholm S, Vahtera J, Kjeldgård L et al (2015) Length of sick leave as a risk marker of hip fracture: a nationwide cohort study from Sweden. Osteoporos Int 26:943-949. https://doi.org/10. 1007/s00198-014-2985-x

29. Black DM, Geiger EJ, Eastell R et al (2020) Atypical femur fracture risk versus fragility fracture prevention with bisphosphonates. N Engl J Med 383:743-753. https://doi.org/10.1056/ NEJMoa1916525

30. Denmark - Physical activity factsheet - WHO/Europe. https:// www.euro.who.int/en/health-topics/disease-prevention/physicalactivity/data-and-statistics/physical-activity-fact-sheets/physicalactivity-country-factsheets/denmark. Accessed 2 Feb 2021

31. SWEDEN Physical Activity Factsheet-WHO Europe. https:// www.euro.who.int/__data/assets/pdf_file/0009/288126/SWEDEN-Physical-Activity-Factsheet.pdf. Accessed 31 Jan 2021

32. Sundhedsstyrelsen (2014) Danskernes sundhed - Den Nationale Sundhedsprofil 2013. https://www.sst.dk/-/media/Udgivelser/2014/ Den-nationale-sundhedsprofil-2013/Danskernes-sundhed,-d-,-Dennationale-sundhedsprofil-2013.ashx. Accessed 19 Jan 2021

33. Färre röker, fler snusar. In: Stat. Cent. http://www.scb.se/hitta-stati stik/artiklar/2018/farre-roker-fler-snusar/. Accessed 19 Jan 2021

34. Razik F, Alexopoulos AS, El-Osta B et al (2012) Time to internal fixation of femoral neck fractures in patients under sixty years-does this matter in the development of osteonecrosis of femoral head? Int Orthop 36:2127-2132. https://doi.org/10.1007/ s00264-012-1619-1

35. Beich A, Gannik D, Saelan H, Thorsen T (2007) Screening and brief intervention targeting risky drinkers in Danish general practice-a pragmatic controlled trial. Alcohol Alcohol Oxf Oxfs 42:593-603. https://doi.org/10.1093/alcalc/agm063

36. Samuel AM, Russo GS, Lukasiewicz AM et al (2016) Surgical treatment of femoral neck fractures after 24 hours in patients between the ages of 18 and 49 is associated with poor inpatient outcomes: an analysis of 1361 patients in the National Trauma Data Bank. J Orthop Trauma 30:89-94. https://doi.org/10.1097/ BOT.0000000000000456

37. Zetterberg CH, Irstam L, Andersson GB (1982) Femoral neck fractures in young adults. Acta Orthop Scand 53:427-435

38. Stearns AT, Jaberoo MC, Ashraf R et al (2009) Displaced intracapuslar hip fractures in the working age alcohol-abusing patient. Scott Med J 54:16-20. https://doi.org/10.1258/rsmsmj.54.1.16

39. Lin JC, Wu CC, Lo C et al (2014) Mortality and complications of hip fracture in young adults: a nationwide population-based cohort study. BMC Musculoskelet Disord 15:362. https://doi.org/ 10.1186/1471-2474-15-362

40. Verettas DA, Galanis B, Kazakos K et al (2002) Fractures of the proximal part of the femur in patients under 50 years of age. Injury $33: 41-45$

41. Upadhyay A, Jain P, Mishra P et al (2004) Delayed internal fixation of fractures of the neck of the femur in young adults. A prospective, randomised study comparing closed and open reduction. J Bone Jt Surg Br 86:1035-1040

42. Jain R, Koo M, Kreder HJ, et al. (2002) Comparison of early and delayed fixation of subcapital hip fractures in patients sixty years of age or less. J Bone Jt Surg Am 84-A:1605-12

43. O'Rourke TK, Wosnitzer MS (2016) Opioid-induced androgen deficiency (OPIAD): diagnosis, management, and literature review. Curr Urol Rep 17:76. https://doi.org/10.1007/ s11934-016-0634-y

44. Cummings SR, Eastell R (2020) Stop (mis)classifying fractures as high- or low-trauma or as fragility fractures. Osteoporos Int 31:1023-1024. https://doi.org/10.1007/s00198-020-05325-z

45. Callréus M, McGuigan F, Akesson K (2014) Country-specific young adult dual-energy X-ray absorptiometry reference data are warranted for T-score calculations in women: data from the peak-25 cohort. J Clin Densitom Off J Int Soc Clin Densitom 17:129-135. https://doi.org/10.1016/j.jocd.2013.03.008

46. Emaus N, Omsland TK, Ahmed LA et al (2009) Bone mineral density at the hip in Norwegian women and men-prevalence of osteoporosis depends on chosen references: the Troms $\varnothing$ Study. Eur J Epidemiol 24:321-328. https://doi.org/10.1007/ s10654-009-9333-z

47. Thoors O, Mellner C, Hedström M (2021) Good clinical outcome for the majority of younger patients with hip fractures: a Swedish nationwide study on 905 patients younger than 50 years of age. Acta Orthop 1-5. https://doi.org/10.1080/17453674.2021.1876996

Publisher's note Springer Nature remains neutral with regard to jurisdictional claims in published maps and institutional affiliations. 


\section{Authors and Affiliations}

\section{Sebastian Strøm Rönnquist ${ }^{1}$ (D) $\cdot$ Bjarke Viberg $^{2} \cdot$ Morten Tange Kristensen $^{3,4,5} \cdot$ Henrik Palm $^{6}$. Jens-Erik Beck Jensen ${ }^{5,7} \cdot$ Carsten Fladmose Madsen ${ }^{8} \cdot$ Kristina E. Åkesson $^{9,10} \cdot$ Søren Overgaard ${ }^{11,12}$. Cecilia Rogmark ${ }^{1}$}

1 Department of Orthopaedics, Lund University, Skåne University Hospital, Malmö and Lund, Sweden

2 Department of Orthopaedic Surgery and Traumatology, Lillebaelt Hospital, University Hospital of Southern Denmark, Kolding, Denmark

3 Departments of Physiotherapy and Orthopaedic Surgery, Copenhagen University Hospital - Amager and Hvidovre, Copenhagen, Denmark

4 Department of Physio- and Occupational Therapy, Copenhagen University Hospital - Bispebjerg and Frederiksberg, Copenhagen, Denmark

5 Department of Clinical Medicine, University of Copenhagen, Copenhagen, Denmark

6 Department of Orthopaedic Surgery, Copenhagen University Hospital - Bispebjerg and Frederiksberg, University of Copenhagen, Copenhagen, Denmark
7 Endocrine Department, Hvidovre University Hospital, Copenhagen, Denmark

8 Department of Orthopaedic Surgery and Traumatology, Odense University Hospital, Odense, Denmark

9 Department of Clinical Sciences, Lund University, Malmö, Sweden

10 Department of Orthopaedics, Skåne University Hospital, Malmö, Sweden

11 Department of Orthopaedic Surgery and Traumatology, Copenhagen University Hospital - Bispebjerg and Frederiksberg, University of Copenhagen, Copenhagen, Denmark

12 Department of Clinical Medicine, Faculty of Health and Medical Sciences, University of Copenhagen, Copenhagen, Denmark 